\title{
Comportamento estrutural de tijolos de solo-cimento utilizando diferentes fontes de água e métodos de cura ${ }^{1}$
}

\author{
Structural behavior of soil-cement bricks using different sources of water and \\ healing methods
}

\section{Comportement structurel de sol ciment briques utilisant différentes sources d'eau et les méthodes de guérison}

\section{Comportamiento estructural del suelo cemento ladrillos utilizando diferentes fuentes de agua y métodos de sanación}

\author{
Alessandro Campos ${ }^{2}$ \\ João Batista do Nascimento Junior \\ Larissa Tessari Brito
}

\begin{abstract}
Recebido em: 07/04/2017; revisado e aprovado em 05/05/2017; aceito em 17/05/2017
DOI: http://dx.doi.org/10.20435/inter.v0i0.1565
\end{abstract}

\begin{abstract}
Resumo: Este trabalho apresenta uma proposta de produção de tijolo solo-cimento a partir de fontes alternativas de captação de água, sendo a rede de abastecimento de água e fontes alternativas como a de rio e estação de tratamento de esgoto (ETE). Para validação do produto, foi realizado testes de tempo e tipo e de cura (natural, câmara úmida e regado) e de resistência à compressão. O trabalho proporcionou resultados apropriados quanto às normas vigentes, contribuindo para um contexto de construção sustentável. Palavras-chave: Produção alternativa na construção; sustentabilidade na construção; tijolo solo-cimento; cura de tijolos solo cimento; aproveitamento da águas residuais.
\end{abstract}

Abstract: This paper presents a proposal for a soil-cement brick production from alternative sources of water, and the water supply network and alternative sources such as river and sewage treatment station (ETE). For product validation, type and time tests and healing (natural, moist and watered) and compressive strength. The work provided appropriate results as the current standards, contributing to a context of sustainable construction.

Keywords: Alternative production in construction; sustainability in construction; soil-cement brick, brick soil-cement healing; use of wastewater.

Résumé : Cet article présente une proposition pour une production de briques de sol-ciment de sources alternatives d'eau et le réseau d'eau potable et les sources alternatives comme le fleuve et station d'épuration (ETE). Pour les tests de validation, de type et de temps de produits et guérison (naturel, arrosée et humide) et résistance à la compression. Le travail fourni des résultats appropriés comme les normes actuelles, contribuant à un contexte de construction durable.

Mots-clés: Production alternative dans la construction; développement durable dans la construction; brique de sol-ciment; brique ciment sol guérison; utilisation des eaux usées.

Resumen: Este documento presenta una propuesta para una producción de ladrillo de suelo cemento de fuentes alternativas de agua y la red de abastecimiento de agua y fuentes alternativas como el río y Planta de tratamiento de aguas residuales (ETE). Para pruebas de validación, el tipo y tiempo de productos y curación (natural, humedad y riego) y resistencia a la compresión. El trabajo proporciona resultados adecuados como las normas vigentes, contribuyendo a un contexto de construcción sustentable.

Palabras clave: producción alternativa en la construcción; sostenibilidad en la construcción; ladrillo de suelocemento ladrillo cemento suelo cicatrización; uso de aguas residuales.

\footnotetext{
${ }^{1}$ Este artigo é parte dos resultados de trabalho de conclusão de curso dos segundo dois autores, sob orientação do primeiro autor.

2 Universidade Católica Dom Bosco (UCDB), Campo Grande, Mato Grosso do Sul, Brasil.
} 


\section{INTRODUÇÃO}

A construção civil apresenta-se como uma atividade de grande importância para a economia brasileira, por meio de pesquisas realizadas em diferentes esferas embasadas nos princípios do desenvolvimento sustentável, abrange sistemas construtivos variados por meio dos materiais utilizados, desde tempos antigos, pois uma das características dos homem, seja a de se adaptar a quase todo tipo de clima terrestre, a partir de adaptação dos abrigos e habitações, e um dos recursos utilizados pela humanidade para possibilitar tal particularidade, seja o uso do solo nas construções (OLGYAY, 1998).

Tem-se que a terra é um dos materiais usados na construção de edificações residenciais. mais antigos, utilizada na fabricação de blocos, para a construção de alvenarias, apresentandose com resistência ao tempo, uma vez que as construções de terra antigas atualmente são patrimônios históricos e culturais (HEATHCOTE, 1995).

O solo mostra-se como importante matéria-prima da construção civil, uma vez que Guettala, Abibsi e Houari (2006) indicam que pelo menos 50\% da população mundial vive em edificações de executadas com solo, seja por meio de tijolos de barro, de telhas de barro ou outros materiais provenientes desse material natural, assim como o cimento. E tanto para a produção de tijolos cozidos como a produção de cimento, ambos sofrem processos de queima.

Devido a esse cenário, estudos demonstram que a utilização de tijolos de solo-cimento prensados a frio, corroboram o emprego desse material e técnica construtiva, pois não exige a queima em sua produção.

As propriedades técnicas desses tijolo se apresentam satisfatórias no emprego do material na construção a partir de estudos da estabilização do solo com o cimento, almejando alternativas de tecnologia na vedação, estrutura e pavimentação dentro da construção civil, em harmonia com as tendências acerca da sustentabilidade, permitindo, dessa maneira, a redução de custo final, pois tem maior quantidade de solo em relação ao cimento, juntamente com a água para amassamento e cura do produto, pois a água é de suma importância para o processo de endurecimento em contato com o cimento.

As alternativas apresentadas neste trabalho tem como objetivo a substituição da água potável proveniente de abastecimento público por: i) água de leito de rio e, ii) água de tratamento de esgoto; seguindo as normas vigentes, e alternativas de execução com diferentes métodos de cura, sendo ao ar natural, regado e câmara úmida.

Dessa maneira, o emprego consciente do solo e cimento aliado com a redução de uso da água potável na produção de tijolos, propõe viabilizar tanto economicamente a produção do tijolo como utilizar os recursos de forma inteligente e embasado nos princípios sustentáveis.

\section{CARACTERÍSTICAS DOS TIJOLOS SOLO-CIMENTO}

A definição de tijolo solo-cimento, também considerado como tijolos ecológicos, resultante da mistura proporcional formada na compactação de solo, cimento e água, são prensados a frio, que após sua cura se tornam endurecido (ABNT, 1992).

Por ser um produto que não sobrevém do processo de queima, evita o consumo de madeira e óleo combustível, beneficiando o aspecto ecológico, podem ser encontrados em algumas literaturas como tijolo ecológico, ao que Souza, Pereira e Segantini (2006), apresentam diversas vantagens no uso do tijolo de solo-cimento, desde sua fabricação ao emprego no canteiro de 
obras, pois tanto equipamentos como materiais utilizados são simples e de baixo custo, sendo admissível produção no próprio canteiro com solo local, o que reduz os custos com energia, transporte, armazenamento, mão de obra, desperdícios e impostos.

Atualmente, o tijolo de solo cimento, também denominado como Bloco de Terra Comprimida, ou BTC, é uma forma moderna da aplicação do solo como material de construção a partir dos materiais prensados a frio (BROWN; EVANS; MORROW, 2014).

A quantidade ideal de materiais, ou seja, o traço da mistura segundo a Associação Brasileira de Cimento Portland (ABCP, 2004), determina que a dosagem de solo e cimento a partir da mistura íntima de solo, cimento e água, procede por meio de parâmetros preordenados e da interpretação dos resultados, resultando na definição da quantidade de água e massa específica aparente dos materiais, que podem sofrer uma alteração devido às características do solo.

Para que possa ser efetuada uma adequada compactação desses materiais, se faz necessário estabelecer que a densidade do solo compactado é resultado da mistura adequada em função do teor de umidade na sua compactação (PINTO, 2006).

A umidade no processo de produção é de suma importância; de acordo com o solo que for utilizado, estabelece-se que a proporção de água na mistura seja uma variável de 5\% a 20\% de água e, segundo a ABNT (1992), a umidade ótima é definida como o valor da umidade correspondente ao valor da massa específica aparente seca máxima, ou seja, quantidade de água ideal para obtenção de compactação estável.

A Portland Cement Association (PCA) sugere que a dosagem ideal para produção de tijolo de solo-cimento, como norma geral, a mistura de maior quantidade de solos com pequenas quantidades de cimento, para que sejam devidamente compactados e curados e, dessa forma, melhore suas propriedades originais de resistência mecânica (ABCP, 2004).

De acordo com Pecoriello e Barros (2004), para os blocos a dosagem dos elementos da mistura pode haver uma variação na proporção em volume de 1:10 a 1:14 (cimento:solo), ao que se deve escolher o melhor traço, dentro dessa faixa, sendo o tijolo de solo-cimento, em forma de adobe ou de BTC, uma das alternativas para a construção de edificações em alvenaria.

\subsection{Compactação da mistura}

Segundo Pecoriello e Barros (2004), a compactação é um fator determinante nos tijolos solo-cimento, pois se faz necessário manter pressões constantes e adequadas, tornando um produto de boa qualidade com uma produção regular dos tijolos (SOUZA; PEREIRA, 2006), o que torna o controle da compactação um dos principais fatores para a confecção de peças de solo-cimento e garante a boa aparência da parede (SILVA, 2005).

Ainda sobre compactação, Barbosa e Mattone (2002) afirmam que compactação com baixas pressões carecem de maior quantidade de cimento para atender a resistência necessária, pois esta está diretamente vinculada à compactação, já que quanto maior a compactação na prensa, mais resistente se torna o tijolo, devido à inovação tecnológica, que possibilitou dessa maneira o aprimoramento de antigas técnicas de construção em terra.

\subsection{Fabricação do tijolo solo-cimento}

Segundo Silva e Castro (2011), a produção do tijolo é feita através da prensagem da mistura dos materiais, o que pode variar conforme os objetivos de sua utilização (resistência, aparência 
superficial etc.) ou conforme o processo a ser empregado, tais como a compactação manual ou a mecânica (PISANI, 2004).

Segundo a CEBRACE (1980), a hidratação do tijolo solo-cimento nos dias iniciais após a moldagem é de grande importância, a que indica que, após as primeiras seis horas da moldagem e ao longo dos sete primeiros dias, devem ser mantidos úmidos para garantir a cura necessária, pois a secagem rápida pode resultar em perda na resistência.

E para seu armazenamento, de acordo com SILVA (2005), após compactação e desmolde, os tijolos devem ser empilhados em superfície plana, em local protegido e coberto ou à sombra, pois, após sua cura, a peça obterá maior resistência à compressão.

\subsection{Resistência à compressão e absorção de água}

Para a verificação da resistência e qualidade dos tijolos, a realização de ensaios em laboratório deve ser feita a partir do teste de resistência à compressão, por meio dos corpos de prova para realização dos testes, ao qual estabelece que o valor mínimo individual dos tijolos deve ser de 1,7 MPa e valor médio de igual ou superior de 2MPa aos 07 dias (ABNT, 1994).

Para o teste de absorção de água, a aparelhagem utilizada no teste consiste em uma balança com sensibilidade de $0,4 \%$ da massa da amostra a ser ensaiada, uma estufa que mantenha temperatura entre $105^{\circ} \mathrm{Ce} 110^{\circ} \mathrm{C}$ e um tanque de imersão, usados com parâmetros uma mesma proporção de amostragem dos corpos de prova utilizados para o teste de resistência à compressão (NBR 10836 [ABNT, 1994]).

Ainda conforme determina a NBR 10836 (ABNT, 1994), quanto ao valor da absorção de resultado encontrado para cada corpo-de-prova é expresso o resultado em porcentagem, e a média de absorção dos corpos-de-prova deve-se fazer com a média dos valores individuais. A média dos valores de absorção de água devem-se apresentar no máximo de $20 \%$ aos sete dias e, aos 28 dias, aos valores individuais devem ser iguais ou menores que $22 \%$.

\subsection{Conceito dos materiais}

Quanto ao uso dos materiais para a produção do tijolo solo-cimento, pode-se dizer que, na produção convencional do produto, adota-se o uso de solo, cimento e água, que, a partir de análises, pode-se constatar no final da pesquisa.

O solo, componente com maior quantidade na mistura, influenciando na qualidade e no custo final do tijolo, tem muita importância (PECORIELLO; BARROS, 2004). Constituído de três componentes (partículas sólidas, água e ar), seu comportamento depende da quantidade relativa de cada um dos componentes (PINTO, 2006). Dentre os tipos de solo, os argilosos permitem uma correção da granulometria por meio de adição de areia, e devido a exercer o solo maior influência na mistura, não se obtém um produto satisfatório ao utilizar um solo inadequado (SILVA, 2009).

Para definir a granulometria do solo, inicialmente encontra-se a umidade do solo, pesando a massa do material úmido e, após 12 horas em estufa (entre $60^{\circ} \mathrm{C}$ e $110^{\circ} \mathrm{C}$ ), pesando a massa seca. Após, deve ser feito o peneiramento fino (peneiras de 1.2, 0.6, 0.42, 0.25, 0.15, $0.075 \mathrm{~mm}^{2}$ ), e pesado todo solo retido nas malhas das peneiras, para estabelecer a curva granulométrica (ABNT, 1984).

Outro importante componente na mistura, o cimento, caracteriza-se como pó fino com propriedades aglomerantes, aglutinantes ou ligantes, que, sob a ação da água, passa por um processo de endurecimento, após o qual, mesmo submetido à ação da água, não sofre 
deformações (MIELI, 2009); e, segundo Pecoriello e Barros (2004), pode-se utilizar qualquer tipo de cimento, entretanto os mais usados são o cimento Portland composto- CP II.

Conforme definido pela NBR 12023 (ABNT, 1992), para produção de tijolo de solo-cimento, deve-se adicionar a água na mistura de solo com cimento, para que atinja a umidade ideal até unificar e estabilizar a umidade da massa, então nomeada mistura úmida.

Como o elemento para coesão dos materiais sólidos na mistura será a água, a quantidade disponível desta em nível mundial abrange volume total 97,5\% de água salgada e 2,5\% de água doce, sendo a água potável para consumo humano disponível somente $0,4 \%$ do volume total do planeta (COMPANHIA DE SANEAMENTO DO ESTADO DE SÃO PAULO [SABESP], 2016).

A água de distribuição da rede de abastecimento público é usada tanto na hidratação do tijolo solo cimento como na cura, que consiste de duas a quatro molhagens diárias, conforme orientações do CEBRACE (1981). Essa água tem parâmetros de qualidade quanto a sua potabilidade, que dispõe sobre os procedimentos de controle e de vigilância da qualidade da água para consumo humano e seu padrão de potabilidade.

Define-se sistema de abastecimento de água para consumo humano como "instalação composta por conjunto de obras civis, materiais e equipamentos, destinada à produção e à distribuição canalizada de água potável para populações, sob a responsabilidade do poder público, mesmo que administrada em regime de concessão ou permissão", conforme essa Cap. II - Art. 4으 da Portaria do decreto 5440 de 2005.

Em Campo Grande, MS, a empresa Águas Guariroba é responsável pelo abastecimento e utiliza dois tipos de captações: $i)$ superficiais e ii) subterrâneas, que, juntamente com a captação, abrange o sistema de abastecimento de água da cidade.

Outra fonte de água para a população pode ser por meio das águas de rio ou canais, que podem ser definidas como cursos d'água, sendo que o escoamento do rio é originário das precipitações pluviais ou nascentes provenientes de águas subterrâneas.

Em mananciais de águas superficiais, rios ou lagos, permite-se a captação direta quando se tem capacidade adequada. Porém, em cursos d'água com vazões suficientes, o fornecimento é garantido com um reservatório de acumulação devido à construção de uma barragem ou dispositivos similares (GARCEZ, 2014).

As águas residuais provenientes de redes de esgoto pode ser definida como o "escoamento líquido constituído de esgoto doméstico e industrial, a água de infiltração e a contribuição pluvial parasitária" (ABNT, 1986).

O esgoto pode ser determinado como um efluente decorrido de edificações provenientes de vasos sanitários, de águas de lavagem ou de limpeza. As águas provenientes de vasos sanitários são compostas por matéria fecal, e possuem matéria orgânica e microrganismos patogênicos, conhecidas como águas imundas. E as águas de lavagem são conhecidas por águas cinzas, tais como as de cozinha, de banhos e lavatórios e de lavanderias (GARCEZ, 2014).

Para desenvolver o tratamento do esgoto, esse procedimento abrange métodos físicos, químicos e biológicos, em função da característica e composição do efluente, com o intuito de remover os sólidos nele presentes. De forma tradicional, pode ser classificado o nível de tratamento, sendo o pré-tratamento, tratamento primário e tratamento secundário (NUVOLARI, 2003).

Para este trabalho, foi mensurada a qualidade da água utilizada tanto como matéria-prima quanto como produto pronto, em análises desses materiais aplicados na produção dos tijolos de 
solo-cimento, o que deu embasamento às análises biológicas para o tijolo pronto e verificação da potencialidade de crescimento microbiano (CUSIDÓ; CREMADES, 2012). Dessa forma, após teste de resistência à compressão, para verificar patologias, fragmentos de tijolos foram imersos em água destilada, de forma a estimular o crescimento de bolores.

Entender a importância que a água tem é relevante para assegurar que as futuras gerações tenham disponibilidade e qualidade adequada em relação à água. Isso é possível a partir do consumo racional, da prevenção e defesa a eventos naturais hidrológicos ou proveniente do inadequado uso desses recursos naturais. Essa proposta vai ao encontro dos usos pertinentes no trabalho, a partir das premissas do desenvolvimento sustentável aplicado na construção civil, utilizando como fonte de água a rede de abastecimento público, água do rio e esgoto doméstico em sua produção.

\section{METODOLOGIA E MATERIAIS}

A pesquisa se fundamenta no estudo da matéria-prima composta pela caracterização física do solo e análise das águas, que deram subsídios para desenvolver os tijolos e, dessa forma, interpretar os resultados da resistência mecânica dos tijolos, absorção de água e análise microbiológica.

Durante toda a pesquisa, foram utilizados os laboratórios da Universidade Católica Dom Bosco (UCDB), e a análise microbiológica foi feita na CETEAGRO - Centro de Tecnologia e Análise do Agronegócio, também na UCDB.

Para a caracterização dos materiais, o solo utilizado foi retirado do CETEAGRO, solo selecionado e livre de matéria orgânica, que posteriormente foi submetido ao teste de granulometria. O teste análise granulométrica do solo foi feito com base nos parâmetros de peneiramento fino da ABNT NBR 7181: 1984, e utilizado solo 100\% passante na peneira 3,0 mm.

Para a produção dos tijolos, o cimento escolhido foi o CP II Z - 32 cimento Portland composto com adição de pozolana da marca Cauê, e, para a utilização das diferentes fontes de água nas misturas, foram utilizadas como água potável a da rede pública, proveniente da torneira do laboratório de materiais de construção.

Para o emprego no trabalho, como água de fonte natural, foi utilizada a água de rio, coletada como amostra em uma fonte na Lagoa da Cruz, local próximo ao laboratório de materiais da UCDB; para acondicionar, proteger e preservar a água, foi empregado um tambor com tampa.

Já a coleta da água de esgoto foi feita na Estação de Tratamento de Esgoto (ETE) da Universidade Católica Dom Bosco (UCDB), localizada próxima à UCDB. O efluente coletado foi da etapa final do processo de tratamento, na saída do tratamento terciário, em que se utilizou um coletor composto por um tubo PVC com uma garrafa plástica de $1 \mathrm{~L}$ na ponta, de forma a retirar a água prevenindo qualquer contato físico, e armazenada em um tambor com tampa rosqueável.

\subsection{Produção dos tijolos}

Para a produção dos tijolos, foi determinado, conforme verificado na bibliografia, um traço definido com teores de 1:10 (cimento:solo). Tal escolha se deu pelo resultado de resistência à compressão mínima adequada, sendo o valor maior médio igual ou superior a 2,0 MPa, conforme exigido pela norma.

Primeiramente, foi separado uma porção de solo in natura, que, após secagem natural, foi destorroado com o auxílio de uma peneira com malha $3 \times 3 \mathrm{~mm}$ e um almofariz de porcelana 
com mão de gral. A produção do tijolo solo-cimento foi feita no traço 1:10, traço definido por volume, com o uso de um recipiente cilíndrico metálico de 10,2 L para os componentes sólidos e um borrifador de 1,5L para a água.

Para comprovação e validação da umidade ideal da mistura, foi realizado ensaio de análise táctil-visual e, a partir desse procedimento, o material foi inserido na máquina de prensagem, utilizando a prensa hidráulica Eco Premium 2500 CH-MA da Eco Máquinas.

Após a prensagem, os tijolos foram dispostos sobre pallets separadamente e reservados no próprio laboratório da UCDB, como apresentado na figura 01.

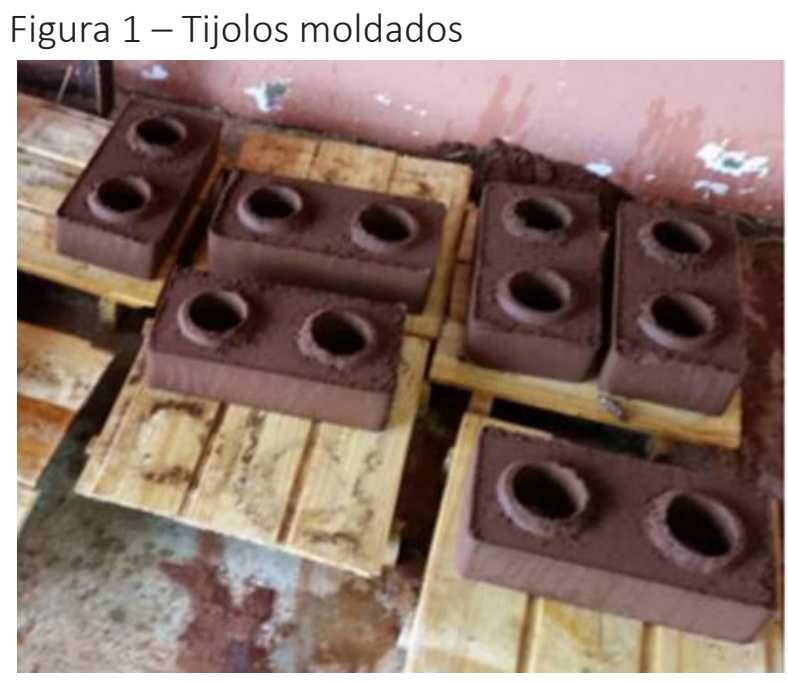

Fonte: Acervo dos autores.

Foram produzidos pelo menos 27 tijolos com cada tipo de água e, depois de prontos, foram divididos em três partes iguais para cada tipo de cura, sendo elas: i) ar natural, ii) rega manual e, iii) câmara úmida.

A cura realizada ao ar natural foi disposta em local livre de umidade e de luz solar direta. Para a rega, a cura foi feita diariamente uma vez ao dia às $15 \mathrm{~h}$, com o auxílio de um regador, utilizando em média $150 \mathrm{ml}$ de água para cada unidade de tijolo, sendo a mesma água com a qual o tijolo foi produzido.

A cura feita na câmara úmida foi monitorada pela equipe técnica da UCDB, sendo ligada com dispositivos aspersores de água pontualmente às 16 h00 e desligado após uma hora. Todos os tijolos foram curados no próprio laboratório de materiais de construção da UCDB.

Para aplicar os testes de resistência à compressão, utilizou-se para o ensaio a prensa hidráulica com capacidade para 500000 lb da marca Forney, modelo F-502F-CPILOT. Conforme as normas, foram retiradas todas as saliências presentes nas faces das amostras, para tornar essas faces totalmente planas e paralelas, e rompidas aos 7 dias e aos 28 dias após sua confecção.

Para o teste de resistência à compressão e determinação do traço, utilizou-se a produção convencional com solo, cimento e água potável retirada da rede de abastecimento, de forma a confirmar que o traço adotado (1:10) está de acordo e atende as exigências quanto à resistência mínima pela norma, para as produções seguintes.

Para o teste de absorção de água, os tijolos foram identificados, pesados em uma balança de precisão de 4 casas decimais em gramas, como "Peso Natural", posteriormente levados à 
estufa a uma temperatura de $110^{\circ} \mathrm{C}$ e deixados durante $24 \mathrm{~h}$, de forma a obter o valor da massa seca (M1) em gramas, posteriormente retirados da estufa e inseridos em baldes com água até a submersão dos tijolos durante um período de $24 \mathrm{~h}$ e, após esse período, retirados e secos para obter massa saturada (M2).

Esse teste foi realizado após os 28 dias de produção, sendo separados conforme cada tipo de produção. Para cada método de produção realizado com cada tipo de água foram separados 4 amostras, usando a seguinte equação:

$$
A \%=\left(M_{2}-M_{1} / M_{1}\right) \times 100
$$

Para a análise microbiológica dos tijolos, foram utilizados fragmentos dos tijolos rompidos aos 7 dias de cada tipo de água da produção e de dois tipos de cura: da câmara úmida e do regado, conforme a figura 02 .

Figura 2 - Processo de análise microbiológica

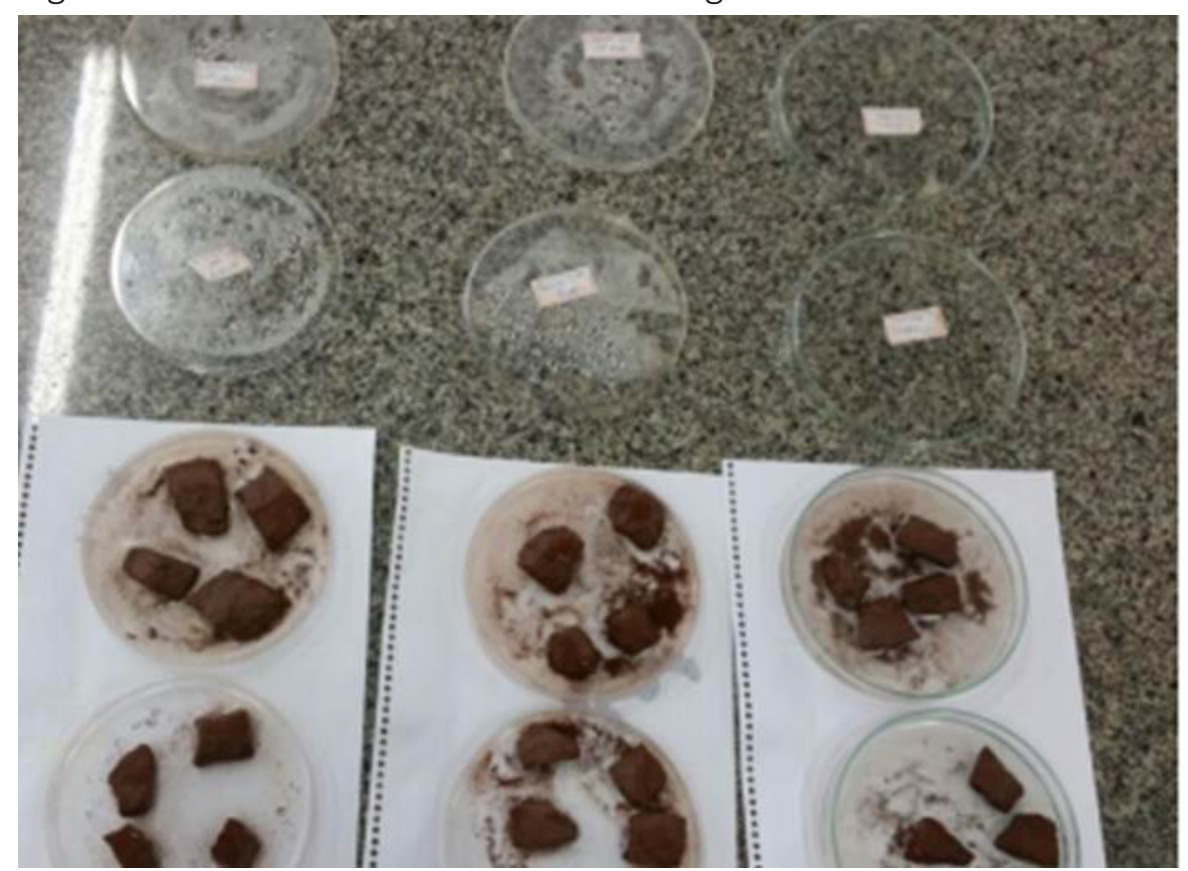

Fonte: Acervo dos autores.

Os fragmentos foram dispostos em 4 partes para cada placa de Petri previamente esterilizadas, de cada variável em estudo, e identificados.

Em cada placa foi adicionada água destilada até cobrir parcialmente os fragmentos, a que as placas ficaram incubadas a uma temperatura de $30^{\circ} \mathrm{C}$ em estufa, sendo observadas diariamente, e por fim, retirou-se uma pequena amostra da água de imersão de cada placa então colocada nas lâminas. Em cada lâmina, foi colocado corante azul e analisado no microscópio.

\section{RESULTADOS E DISCUSSÕES}

Os resultados alcançados na pesquisa serão apresentados conforme os objetivos inicialmente estabelecidos. Assim foram realizados os testes com os materiais e com os tijolos solo-cimento produzidos com as três fontes de água e por meio de três métodos de cura. 
$\mathrm{Na}$ análise do solo, os valores encontrados da massa seca retida nas peneiras e as suas respectivas porcentagens são demonstrados na tabela 1. E a curva granulométrica resultante do peneiramento fino do solo, sendo um material $100 \%$ passante na peneira de $4,8 \mathrm{~mm}$.

Tabela 1 - Resultado do peneiramento fino do solo

\begin{tabular}{|c|c|c|c|c|}
\hline Peneira & Abertura (mm) & Solo retido (g) & $\begin{array}{c}\text { Solo retido } \\
\text { acumulado }(\mathbf{g})\end{array}$ & $\begin{array}{c}\text { Massa passante } \\
\mathbf{( \% )}\end{array}$ \\
\hline 16 & 1,19 & 0,073 & 0,073 & 99,94 \\
\hline 30 & 0,59 & 0,987 & 1,06 & 99,11 \\
\hline 40 & 0,42 & 5,142 & 6,202 & 94,83 \\
\hline 50 & 0,297 & 5,806 & 12,008 & 89,99 \\
\hline 100 & 0,149 & 13,191 & 25,199 & 79 \\
\hline 200 & 0,075 & 5,103 & 30,302 & 47,75 \\
\hline
\end{tabular}

Fonte: Próprios autores.

Para verificar a absorção de água dos tijolos, foram deixados os tijolos ao ar natural e, somente aos 28 dias de idade, foram secos em estufas e colocados em imersão na água.

Conforme determina a norma, de acordo com o peso da massa da amostra, pode-se realizar a análise do teste de absorção de água, e os valores encontrados da massa seca e massa saturada (com água) são demonstrados na tabela 2, assim como o valor comparativo analisado para o teste de absorção de água foi feito com a média dos valores encontrados das amostras, no qual se pôde fazer uma média dos valores da absorção de água, que também podem ser observados na tabela 2.

Tabela 2 - Resultado do peneiramento fino do solo

\begin{tabular}{|c|c|c|c|c|}
\hline \multirow{2}{*}{ Água } & \multicolumn{4}{|c|}{ Massa (g) } \\
\cline { 2 - 5 } & Natural & Seca $-\mathbf{M}_{\mathbf{1}}$ & Saturada $-\mathbf{M}_{\mathbf{2}}$ & Absorção de água (\%) \\
\hline Rede & 2479,75 & 2382,50 & 2911,30 & 22,25 \\
\hline Rio & 2920,70 & 2816,07 & 3424,10 & 21,58 \\
\hline ETE & 3035,90 & 2918,35 & 3626,78 & 24,29 \\
\hline
\end{tabular}

Fonte: Próprios autores.

Observou-se que os tijolos produzidos com água de ETE são mais porosos, apresentando maior absorção de água, o que irá influenciar sua resistência à compressão.

Já os tijolos confeccionados com água de rio obtiveram melhores resultados quanto a sua resistência, e menor índice de absorção, de acordo com as exigências da norma.

Os primeiros resultados quanto resistência à compressão foram obtidos a partir de três amostras confeccionadas com água da rede de abastecimento público, por ser uma produção convencional para o mercado.

Dessa maneira, foi determinado para definir o melhor traço na produção de todos os tijolos solo-cimento, e apresentar de maneira adequada a produção dos demais tijolos com diferentes fontes de água e cura.

O primeiro teste de resistência à compressão fez-se para determinação do traço de referência, e foram encontrados os valores apresentados conforme a tabela 03, referente aos resultados de rompimento aos 7 dias, e tabela 04, referente aos resultados de 28 dias. 
Quanto a esses resultados, percebeu-se que, conforme foi regado durante mais dias o corpo de prova, obteve-se uma resistência maior à compressão em relação às outras curas durante os 28 dias, enquanto que, para os 7 dias, o que apresentou maior resistência foi ao ar natural.

Porém, todas as amostras para todas as curas obtiveram a resistência exigida em norma, segundo a NBR 10834, que é valor superior a $2 \mathrm{MPa}$.

Com os resultados identificados, foi evidenciado que o traço 1:10 está de acordo com os parâmetros estabelecidos pela norma, adotando-o para toda a produção.

Os resultados dos tijolos produzidos com água da rede e da chuva rompidos aos 7 dias são observados na tabela 3.

Tabela 3 - Resultado do teste de resistência à compressão aos 7 dias

\begin{tabular}{|c|c|c|c|c|}
\hline \multirow{2}{*}{ Cura } & $\begin{array}{c}\text { Corpos de } \\
\text { prova }\end{array}$ & Rede & Rio & ETE \\
\cline { 3 - 5 } & Resistência (MPa) & Resistência (MPa) & Resistência (MPa) \\
\hline \multirow{4}{*}{$\begin{array}{c}\text { AR } \\
\text { NATURAL }\end{array}$} & 2 & 4,30 & 4,70 & 5,25 \\
\cline { 2 - 5 } & 2 & 5,30 & 4,67 & 5,82 \\
\cline { 2 - 5 } & 3 & 5,30 & 4,49 & 5,47 \\
\hline \multirow{4}{*}{ REGADO } & 4 & 5,87 & 4,67 & 5,52 \\
\cline { 2 - 5 } & 2 & 5,89 & 5,27 & 3,58 \\
\cline { 2 - 5 } & 3 & 5,51 & 5,75 & 2,61 \\
\hline \multirow{4}{*}{ CÂMARA ÚMIDA } & 4 & 5,57 & 5,78 & 4,52 \\
\cline { 2 - 5 } & 1 & 5,63 & 4,81 & 3,90 \\
\cline { 2 - 5 } & 2 & 5,20 & 4,68 & 2,98 \\
\cline { 2 - 5 } & 3 & 5,48 & 5,52 & 3,12 \\
\hline
\end{tabular}

Fonte: Próprios autores.

Os resultados do teste de resistência aos 28 dias da produção dos tijolos feito com água do rio e esgoto são observados na tabela 04.

Tabela 4 - Resultado do teste de resistência à compressão aos 28 dias

\begin{tabular}{|c|c|c|c|c|}
\hline \multirow{2}{*}{ Cura } & $\begin{array}{c}\text { Corpos de } \\
\text { prova }\end{array}$ & Rede & Rio & ETE \\
\cline { 2 - 5 } & 1 & Resistência (Mpa) & Resistência (Mpa) & Resistência (Mpa) \\
\hline \multirow{4}{*}{ AR } & 2 & 6,98 & 6,46 & 7,31 \\
\cline { 2 - 5 } & 3 & 6,53 & 6,33 & 7,46 \\
\cline { 2 - 5 } & 4 & 7,06 & 7,22 & 6,38 \\
\hline \multirow{4}{*}{ REGURAL } & 1 & 6,89 & 7,68 & 6,4 \\
\cline { 2 - 5 } & 2 & 6,89 & 4,17 & 3,32 \\
\cline { 2 - 5 } & 3 & 6,38 & 4,61 & 3,85 \\
\cline { 2 - 5 } & 4 & 6,56 & 4,46 & 4,01 \\
\hline \multirow{3}{*}{$\begin{array}{c}\text { CÂMARA } \\
\text { ÚMIDA }\end{array}$} & 1 & 4,63 & 4,76 & 4,16 \\
\cline { 2 - 5 } & 2 & 7,43 & 7,01 & 3,76 \\
\cline { 2 - 5 } & 3 & 7,54 & 7,87 & 4,21 \\
\hline
\end{tabular}

Fonte: Próprios autores. 
Os valores da tabela 05 e tabela 06 apresentam as médias dos valores dos testes realizados com a cura aos 7 dias e 28 dias respectivamente.

Tabela 5 - Resultado das médias do teste de resistência à compressão aos 7 dias

\begin{tabular}{|c|c|c|c|c|}
\hline \multirow{2}{*}{ Cura } & Corpos de & Rede & Rio & ETE \\
\cline { 3 - 5 } & prova & Resistência (Mpa) & Resistência (Mpa) & Resistência (Mpa) \\
\hline AR NATURAL & 1 a 4 & 5,19 & 4,63 & 5,52 \\
\hline REGADO & 1 a 4 & 5,65 & 5,40 & 3,65 \\
\hline CÂMARA UMIDA & 1 a 41 & 5,36 & 5,28 & 3,82 \\
\hline
\end{tabular}

Fonte: Próprios autores.

Tabela 6 - Resultado das médias do teste de resistência à compressão aos 28 dias

\begin{tabular}{|c|c|c|c|c|}
\hline \multirow{2}{*}{ Cura } & Corpos de & Rede & Rio & ETE \\
\cline { 3 - 5 } & prova & Resistência (Mpa) & Resistência (Mpa) & Resistência (Mpa) \\
\hline AR & 1 a 4 & 6,87 & 6,92 & 6,89 \\
\hline REGADO & 1 a 4 & 6,11 & 4,50 & 3,83 \\
\hline CÂMARA UMIDA & 1 a 4 & 6,32 & 7,36 & 4,08 \\
\hline
\end{tabular}

Fonte: Próprios autores.

A partir da tabela apresentada anteriormente, um comparativo com as médias dos valores de resistência à compressão deu subsídios para maior compreensão dos experimentos, suas relações entre resistência dos tijolos e quanto ao tipo de produção conforme a água utilizada.

O tijolo produzido com água de ETE e com cura ao ar natural foi o que apresentou maior resistência à compressão aos 7 dias, em contrapartida, foi o que apresentou menor resistência com a técnica da rega, e o que mais apresentou variabilidade nos resultados.

Os tijolos que apresentaram pouca variabilidade nos resultados do teste de resistência à compressão foram os tijolos confeccionados com água da rede de abastecimento público. O tijolo produzido com água de rio e com cura na câmara úmida foi o que apresentou maior resistência à compressão aos 28 dias, e também o que mais apresentou variabilidade nos resultados.

E, neste gráfico, percebe-se que todos os tijolos produzidos e curados ao ar natural mantiveram os mesmos parâmetros de resistência à compressão. Para que possam ser efetuados os parâmetros e comparativos, foi realizada a análise das médias aos 07 dias e aos 28 dias. Para que possam ser diagnosticados com maior clareza, foi idealizado um gráfico simultâneo para rompimento aos 7 dias e aos 28 dias, conforme apresentado na figura 3. 
Figura 3 - Gráfico das médias de resistência à compressão aos 7 dias e 28 dias

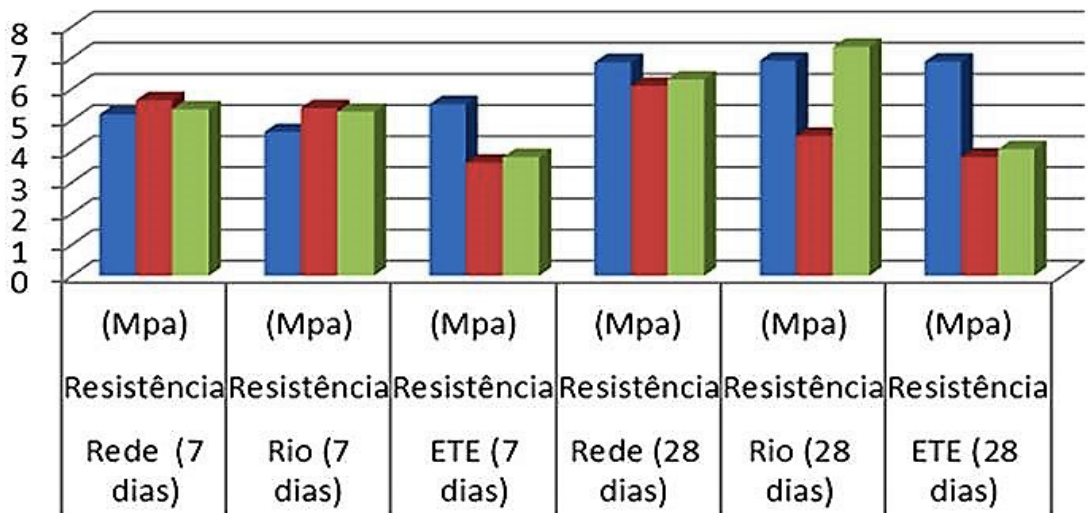

a AR NATURAL GEGADO —CAMMARA UMIDA

Fonte: Próprios autores.

De maneira geral, as médias dos valores apresentam-se maiores aos 28 dias do que aos 07 dias, com exceção dos produzidos com ETE com os métodos de cura regado e de câmara úmida, que não apresentaram esse crescimento com o tempo. O tijolo produzido com água da rede pública de abastecimento e com cura ao ar natural foi o que apresentou maior aumento da resistência usando a cura por mais dias, de modo que se pôde notar que apresentou uma queda foi o regado com água de rio.

Os tijolos produzidos com a água de ETE tiveram resultados mais satisfatórios com a cura aos 28 dias ao ar natural. Para os da rede de água e de rio, foram com a cura aos 07 dias e aos 28 dias e curados na câmara úmida. Conforme a produção alterna com o tipo de água utilizada e o método de cura, pode-se encontrar valores que variam pouco entre si, se comparar sua idade, portanto, os valores se mostram diferentes quanto às análises com o tempo de cura.

De um perfil geral, pode-se dizer que os resultados com melhor desempenho quanto ao objetivo da pesquisa são as amostras que deixam com a cura por mais tempo, adotando 28 dias o ideal para sua utilização. Essa constatação pode ser observada nos resultados que apresentaram resistência adequada quanto às exigências normativas, assim também as análises e testes realizados apresentaram resultados satisfatórios.

Dessa forma, buscou-se alcançar com a pesquisa, analisar e identificar a boa resistência à compressão e absorção de água, aparência, desempenho, durabilidade de acordo com as exigências normativas, e consequentemente, incrementar a pesquisa acerca da sustentabilidade e inovação tecnológica na construção civil, preservando um recurso natural, de valor econômico e ambiental que é usado para abastecimento humano, alinhado ao pensamento de aproveitamento de águas que são usadas para fins não potáveis, e de fácil captação.

\section{CONCLUSÃO}

A partir dos estudos e das análises realizadas, constatou-se que a proposta de utilização de outras fontes de água torna-se viável uma vez que a captação de água não potável é de fácil aquisição e de custo relativamente baixo, sendo possível utilizar outras fontes que não seja a água potável na produção do tijolo utilizado na construção civil.

Durante a realização da pesquisa, os métodos de cura demonstraram que, se for maior o tempo de cura, melhor será o desempenho do tijolo em relação a sua resistência, e as análises 
comparativas apresentaram resultados coerentes, com pequenas variações que deram suporte e validação ao estudo.

Conclui-se que a utilização de águas não potáveis para produção dos tijolos é uma alternativa benéfica para a construção sustentável, visando à sua aplicação e expansão do uso na construção civil.

Dessa maneira, a água dos leitos dos rios e também a água tratada da rede de esgoto, demonstraram não afetar a composição do tijolo por meio da presença de microrganismos, sendo uma alternativa ao identificar se as outras fontes de água, além da potável, são capazes de manter a resistência do tijolo e assim, possibilitar que a indústria da construção civil, reduza em parte a agressão ao meio ambiente, tornando as construções ecologicamente sustentáveis.

É necessário que novas pesquisas sejam desencadeadas com o objetivo de propor uma produção do tijolo mais econômica e sustentável. Assim, pesquisas que busquem incluir novos componentes no processo produtivo, à base de água não potável, poderão contribuir com esse objetivo.

\section{REFERÊNCIAS}

ABCP. Dosagem das misturas de solo-cimento- normas de dosagem e métodos de ensaios. 3 ed. São Paulo: $A B C P, 2004$.

ABNT. NBR 10834: Bloco vazado de solo-cimento sem função estrutural. Rio de Janeiro, out. 1994a.

ABNT. NBR 10836: Bloco vazado de solo-cimento sem função estrutural-determinação da resistência à compressão e da absorção de água. Rio de Janeiro, out. 1994b.

ABNT. NBR 12023: Solo-cimento- ensaio de compactação. Rio de Janeiro, abr. 1992.

ABNT. NBR 9648: Estudo de concepção de sistema de esgoto sanitário. Rio de Janeiro, nov. 1986.

ABNT. NBR 7181: Solo- análise granulométrica- método de ensaio. Rio de Janeiro, dez. 1984.

BARBOSA, N. P.; MATTONE, R. Construção com terra crua. In: SEMINÁRIO IBERO AMERICANO DE CONSTRUÇÃO COM TERRA, 1., Salvador, 2002. Anais [...]. Salvador: Projeto PROTERRA, 2002.

BROWN, J.; EVANS, M.; MORROW, C. Model Block Press, Mechanical Engineering Department. San Luis Obispo: California Polytechnic State University, 2014.

CEBRACE. Solocimento na construção de escolas - SC01. 2. ed. Rio de Janeiro, MEC/CEBRACE, 1981. 39p. il. (sistemas construtivos 2).

CUSIDÓ, J. A.; CREMADES, L. V. Environmental effects of using clay bricks produced with sewage sludge: leachability and toxicity studies. Waste Management, v. 31, p. 1202-08, 2012.

GARCEZ, L. N. Elementos de engenharia hidráulica e sanitária. 2. ed. São Paulo: Blucher, 2014. 346p.

GUETTALA, A.; ABIBSI, A; HOUARI, H. Durability study of stabilized earth concrete under both laboratory and climatic conditions exposure. Construction and Building Materials, v. 20, p. 119-27, 2006.

HEATHCOTE, K. A. Durability of earthwall buildings. Building Mater, v. 9, n. 3, p. 185-9, 1995. 
MIELI, P. H. Avaliação do tijolo modular de solo-cimento como material na construção civil. Orientador: Célio Albano da Costa Neto. 2009. 48 p. Projeto de Conclusão de Curso (Graduação em Engenharia de Materiais)- Universidade Federal do Rio de Janeiro (UFRJ), Rio de Janeiro, 2009.

NUVOLARI, A. As diversas opções de tratamento do esgoto sanitário. In: NUVOLARI, A. (Coord.). Esgoto sanitário: coleta, transporte, tratamento e reuso agrícola. São Paulo: E. Blücher, 2003. p. 227-380.

OLGYAY, V. Arquitectura y clima - manual de diseño bioclimático para arquitectos y urbanistas. [S.I.]: Gustavo Gilli, 1998.

PECORIELLO, L. A.; BARROS, J. M. de C. Alvenarias de tijolo solo-cimento. Revista Téchne, São Paulo, n. 87, jun., 2004.

PINTO, C. de S. Curso básico de mecânica dos solos em 16 aulas. 3. ed. São Paulo: Oficina de Textos Editora, 2006.

PISANI, M. A. J. Taipas: a arquitetura de terra. Revista Sinergia, São Paulo, v. 5, n. 1, p. 09-15, 2004.

SABESP. Água no Planeta. [S.d.]. Disponível em: http://site.sabesp.com.br/site/. Acesso em: 29 mar. 2016.

SILVA, S. R. Tijolos de solo-cimento reforçado com serragem de madeira. Dissertação (Mestrado em Engenharia de Estruturas). Orientador: Edgar Vladimiro Mantilla Carrasco. 2005. 202 f.- Universidade Federal de Minas Gerais (UFMG), Belo Horizonte, MG, 2005.

SILVA, F. S.; CASTRO, P. A. S. Incentivo ao uso de produtos de baixo impacto ambiental através da disciplina de materiais de construção civil. Salto, SP: CEUNSP, 2011.

SOUZA, M. I., PEREIRA, J. A.; SEGANTINI, A. A. S. Tijolos solo-cimento com resíduos de construção. Revista Téchne, São Paulo, n. 113, ago. 2006.

\section{Sobre os autores:}

Alessandro Campos: Doutorando em Engenharia de Produção (UNIMEP). Mestre em Engenharia das Edificações e Saneamento (UEL). Graduado em Arquitetura e Urbanismo (CESULON). Professor na Universidade Católica Dom Bosco (UCDB). E-mail: alessandro@ucdb.br

João Batista do Nascimento Junior: Especialização em MBA Gestão de Projetos pelo Centro Universitário da Grande Dourados. Graduação em Engenharia Civil pela Universidade Católica Dom Bosco. Engenheiro civil da ENGETEC Assessoria e Consultoria.E-mail: joao_b.jr@hotmail.com

Larissa Tessari Brito: Graduação em Engenharia Ambiental e Sanitária pela Universidade Católica Dom Bosco. Desenhista Projetista da Empresa de Saneamento de Mato Grosso do Sul. E-mail: lari_tessa@hotmail.com 